\title{
Medicalização dos Desvios de Comportamento na Infância: Aspectos Positivos e Negativos
}

Medicalization Of Deviant Behavior In Children: Positive And Negative Features

Medicalización De Los Desvíos De Comportamiento En La Infancia: Aspectos Positivos Y Negativos

Fabíola Stolf Brzozowski \&

Sandra Noemi Cucurullo de Caponi

Universidade Federal de Santa Catarina

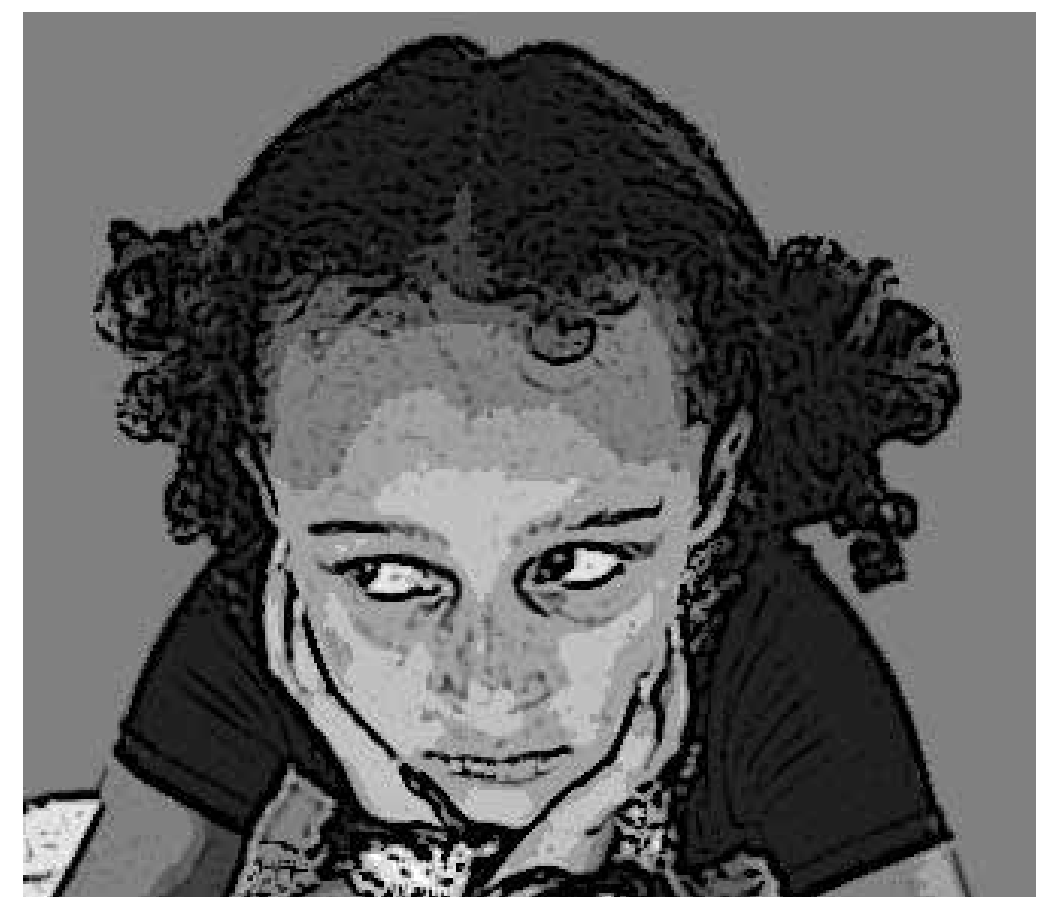


Resumo: A medicalização dos comportamentos desviantes na infância é apresentada como uma estratégia eficaz para lidar com crianças que apresentam algum tipo de dificuldade, sem que, no entanto, as dificuldades desse processo sejam claramente expostas. O processo de medicalização, porém, é complexo e apresenta muitos resultados negativos. Dentro desse contexto, nosso objetivo é refletir sobre essas dificuldades. Primeiramente, apresentamos como se dá a relação entre medicalização e infâcia. Em seguida, discutimos alguns aspectos considerados positivos e negativos da medicalização. Para finalizar, consideramos que enquadrar uma criança em um diagnóstico psiquiátrico apresenta sérias consequências indesejáveis, e acaba sendo mais útil para a sociedade e para o entorno da criança do que para a própria criança.

Palavras-chave: Medicalização. Transtorno da falta de atenção com hiperatividade. Distúrbio da atenção. Desenvolvimento infantil.

\begin{abstract}
The medicalization of deviant behaviors during childhood is usually presented as an effective strategy to deal with troublesome children, but the problems associated with medicalization are not frequently exposed. Even so, the process of medicalization is complex and may present many negative results. In this context, our aim is to discuss these difficulties. First, we present an overview of the relationship between medication and childhood. After that, we discuss some positive and negative aspects of medicalization. Finally, we conclude that framing a child under a psychiatric diagnosis is often more beneficial for the society and the child's surroundings than it is for the child herself.
\end{abstract}

Keywords: Medicalization. Attention deficit disorder with hyperactivity. Attention deficit disorder. Childhood development.

Resumen: La medicalización de los comportamientos desviantes en la infancia es presentada como una estrategia eficaz para manejar niños que presentan algún tipo de dificultad, sin que, sin embargo, las dificultades de ese proceso sean claramente expuestas. El proceso de medicalización, sin embargo, es complejo y presenta muchos resultados negativos. En ese contexto, nuestro objetivo es reflexionar sobre esas dificultades. Primero, presentamos como se da la relación entre medicalización e infancia. Enseguida, discutimos algunos aspectos considerados positivos y negativos de la medicalización. Para finalizar, consideramos que encuadrar un niño en un diagnóstico psiquiátrico presenta serias consecuencias indeseables, y acaba siendo más útil para la sociedad y para el entorno del niño de lo que para el propio niño.

Palabras clave: Medicalización. Trastorno de la falta de atención con hiperactividad. Disturbio de la atención. Desarrollo infantil.

Medicalização é o processo no qual problemas que não eram considerados de ordem médica passaram a ser vistos e tratados como problemas médicos. Para Peter Conrad (1992), isso significa dizer que um problema foi definido em termos médicos, por meio do uso da linguagem médica, da adoção de explicações médicas e de um tratamento para a condição. Os cuidados e os tratamentos médicos se desenvolveram muito nas últimas décadas, revelando terapêuticas para doenças antes letais. Porém, nesse mesmo sentido, o campo médico se expandiu consideravelmente, englobando muitos problemas que não eram considerados médicos, processo que Ivan Illich (1975) chamou de medicalização da vida. Outros autores pioneiros quando se fala em medicalização foram Thomas Szasz
(1974) e Michel Foucault (2001). Em termos do debate atual sobre o tema, podemos citar Conrad (2007), Horwitz (2007), Timimi (2002) e Moyses e Collares (2010).

A medicalização pode ocorrer tanto em casos de desvios de comportamento quanto de processos naturais da vida. Alguns exemplos de processos naturais da vida medicalizados incluem sexualidade, nascimento, desenvolvimento infantil, tensão pré-menstrual (TPM), menopausa, envelhecimento e o processo de morrer. Já dentre os desvios podemos citar loucura, alcoolismo, homossexualidade, hiperatividade e dificuldades de aprendizagem, problemas alimentares (obesidade e anorexia), abuso infantil, jogo compulsivo, infertilidade e transexualidade, 
dentre outros (Conrad, 1992). Este artigo propõe uma discussão sobre a medicalização dos desvios de comportamento da infância.

Consideramos como desvio de comportamento qualquer conduta que destoe do que é socialmente desejável, mas que nem sempre representa uma entidade nosológica. Muitos desses desvios, porém, são considerados atualmente transtornos mentais (ou então seus sintomas), o que caracteriza um processo de medicalização desse tipo de conduta. Um exemplo de desvios medicalizados de comportamento medicalizado, principalmente a partir da metade do século XX, são a falta de atenção e a hiperatividade, sintomas principais do transtorno do déficit de atenção com hiperatividade (TDAH).

Desde a década de 70, fala-se em medicalização, e, com o passar dos anos, mais problemas foram sendo incorporados ao campo médico. Seria muita ilusão pensar que a medicalização traga consigo somente aspectos negativos, já que a sociedade a aceita há muito tempo (pelo menos desde o século XIX). Mas também não podemos negar que há uma supervalorização de determinados diagnósticos, o que faz que muitas pessoas normais sejam diagnosticadas com transtornos mentais, por exemplo.

Dentro desse contexto, temos como objetivo refletir sobre o processo de medicalização infantil, seus aspectos positivos e negativos e suas possíveis consequências. Para isso, primeiramente apresentaremos algumas definições e aspectos sobre medicalização e sua relação com a infância. Depois, nós nos propomos refletir sobre alguns aspectos positivos e negativos dessa medicalização, tendo como referência principal o autor Peter Conrad. Por fim, serão apresentadas algumas considerações finais, com as visões das autoras sobre os elementos apresentados.

\section{Infância e medicalização}

Como já foi dito anteriormente, tratamos aqui de um tipo específico de medicalização, que é a dos comportamentos considerados desviantes. Mas o que seriam os desvios? Para Conrad e Schneider (1992), os desvios consistem em categorias de julgamentos sociais negativos que são construídos e aplicados socialmente, geralmente de alguns grupos de uma comunidade para outros. O desvio é um fenômeno universal, e a noção de que toda sociedade tem normas sociais já pressupõe a existência do desvio. Grupos sociais criam regras e impõem suas definições para os outros membros por meio do julgamento e da aprovação social; por isso, o desvio é contextual, e a definição e a aprovação do desvio envolvem relações de poder.

A medicalização dos desvios é possível por meio da flexibilização dos limites do que é considerado normal e do que não é. A era moderna da classificação diagnóstica em saúde mental se originou nos asilos, porém hoje os manuais diagnósticos não estão restritos a esses espaços. Suas categorias parecem englobar não somente uma pequena minoria da população, mas quase todos nós. Os diagnósticos psiquiátricos incluem uma variedade de condições que se situam, de acordo com Rose (2006), na fronteira da normalidade, tais como ansiedade, pânico, depressão leve a moderada, transtornos de personalidade, TDAH, transtornos de conduta e transtornos do espectro autista.

Se tomarmos como exemplo a depressão, principalmente os casos mais leves, percebemos que existe uma falta de definição objetiva dos critérios diagnósticos, o que permite que qualquer estado de ânimo que resulte em abatimento possa ser 
combinação de sintomas como dificuldades de concentração e falta de energia caracterizam o quadro clínico, mesmo que essa combinação possa ocorrer em algum momento da vida de qualquer pessoa (Hernaez, 2010). medicalizado. Uma combinação de sintomas como dificuldades de concentração e falta de energia caracterizam o quadro clínico, mesmo que essa combinação possa ocorrer em algum momento da vida de qualquer pessoa (Hernaez, 2010).

Voltando ao tema da infância, é possível observar que grande parte dos desvios ocorridos nessa época da vida são notados na escola e descobertos a partir do momento em que a criança desenvolve algum problema de aprendizagem. Como exemplo, podemos pensar na alfabetização: se uma criança não aprende a ler com determinada idade, ou então se tem dificuldade em prestar atenção na sala de aula, isso pode ser considerado um desvio, e a criança pode, atualmente, ser encaminhada a um profissional da saúde para averiguar seu quadro. Os desvios da infância, dessa forma, são aqueles relacionados com a quebra de normas e de regras impostas socialmente, como, por exemplo, a falta de atenção e a agitação em sala de aula.

Mas nem sempre foi assim. Até alguns anos atrás, os problemas escolares eram resolvidos na escola ou por meio da família. Não havia preocupação da área da saúde com esse tipo de comportamento, talvez porque a Medicina não fosse tão resolutiva quanto hoje e, em consequência, tivesse preocupações mais urgentes para lidar, tais como infecções fatais (facilmente controladas atualmente pela administração de antibióticos, por exemplo). Muito antes disso, a criança era um pequeno adulto, sendo que a infância não era considerada uma fase diferencial da vida. O sentimento de infância teve início no século XIII, mas o seu desenvolvimento e estabelecimento foram se dando apenas a partir do século XVI e durante o século XVII. A criança era vista como um pequeno adulto, e participava do mundo dos adultos (por meio de vestimentas, jogos e trabalho, dentre outros). A etapa de vida da criança era considerada um período de transição, rapidamente superada e sem importância. Isso não quer dizer que as crianças eram abandonadas ou negligenciadas, o que não existia era a consciência da particularidade infantil (Ariès, 1981).

A infância se tornou um tempo particular da constituição humana, que necessita de preparo e de prevenção para produzir indivíduos capazes para o trabalho e saudáveis, que fizessem parte do corpo social. Assim, instituiu-se a necessidade de a infância ser gerida. As intervenções dirigidas às escolas e às famílias tiveram origem, de maneira geral, nas teorias higienistas, nas teorias médicas sobre degeneração, nas concepções da puericultura e no desenvolvimento de técnicas da Psicologia do desenvolvimento (Guarido, 2010).

O processo de medicalização está diretamente ligado ao que é considerado um desvio social e ao controle social. Ao mesmo tempo em que a área da saúde foi entrando na vida familiar e escolar, a Medicina foi assumindo o papel de agente de normalização dos desvios, ficando responsável por comportamentos que até então eram da esfera de outras instituições, tais como aprendizagem e criminalidade. Em outras palavras, certas condutas, como a delinquência e a sexualidade, por exemplo, foram incorporadas ao campo médico em uma tentativa de resolução de problemas e de normalização dessas condutas.

Paralelamente ao surgimento do sentimento da infância, ocorreu também uma evolução da instituição escolar, também responsável pelo controle dos comportamentos das crianças. No século XIII, os chamados colégios eram asilos para estudantes pobres, e lá não se 
ensinava. Só a partir do século XV esses locais passaram a ser de ensino, e foram abertos para jovens de fora da instituição. Todo o ensino das artes passou a ser ministrado nos colégios, e deu origem aos grandes colégios do século XV ao XVII, como os dos jesuítas. O estabelecimento de regras rígidas de disciplina completou a evolução da escola medieval (que se resumia a uma simples sala de aula) ao colégio moderno (instituição de ensino, de vigilância e de controle) (Ariès, 1981).

A partir da metade do século XIX e do início do século XX, juntamente à difusão da educação escolar, a preocupação com a saúde e com a higiene se tornou uma das incumbências da escola. Como exemplo, podemos citar o fato de que a escola participa ativamente de campanhas que visam ao combate de endemias e epidemias, como as de vacinação, e também da difusão de meios de prevenção e de preservação da saúde (Rocha, 2003). A higienização na escola abriu caminho para que a saúde entrasse na instituição escolar e ali permanecesse, tornando possível e aceitável a identificação e o encaminhamento ao médico de crianças com problemas de comportamento, a partir do momento em que esses problemas fossem considerados doenças ou transtornos.

Escolares que são mais ativos, agitados e que são pouco atentos sempre foram um problema para pais e professores. A novidade está no fato de se acreditar que esses comportamentos sejam sintomas de um transtorno mental tratável com medicamentos (Conrad \& Schneider, 1992). As pesquisas sobre bioquímica cerebral dão esperança para o desenvolvimento de uma metodologia de ensino, e têm sustentado explicações sobre os comportamentos das crianças e as causas dos fracassos escolares (Guarido, 2010).
Desde a emergência da hiperatividade como um diagnóstico, ocorreram algumas mudanças na definição e nas características desse transtorno, o que revela a elasticidade das categorias médicas aplicadas a condutas previamente consideradas moralmente problemáticas. Vejamos o exemplo do TDAH: inicialmente, o diagnóstico era feito em crianças muito ativas, impulsivas e distraídas (principalmente meninos). Nos anos 80 , o foco mudou da hiperatividade para a dificuldade em manter a atenção. O tratamento continuou o mesmo, mas a categoria diagnóstica expandiu-se e tornouse mais inclusiva. Atualmente, o TDAH pode englobar também adolescentes, adultos e meninas que não são agitadas (Conrad, 2007).

\section{Aspectos positivos}

Com o sucesso da Medicina no controle das doenças infecciosas, o crescimento da biomedicina científica, a regulação da educação médica e a organização política e o lobby das associações médicas, o prestígio da profissão médica aumentou no último século (Conrad \& Schneider, 1992). E, seguindo essa tendência, os tratamentos médicos para comportamentos e sofrimentos humanos são vistos, atualmente, como algo normal, corriqueiro e até como exemplos de progresso, de tecnologia e de inovação.

No sentido de tecnologia, a visão biologicista é hegemônica nas ciências da saúde, o que sustenta uma medicina que busca evidências, objetivação dos sintomas e uso de medicamentos psicotrópicos como base para o tratamento dos sofrimentos humanos. Esses medicamentos são considerados, por muitas pessoas e profissionais de saúde, bens de consumo, e podem estar relacionados à qualidade de vida, ao bem-estar e à felicidade (Guarido, 2010). 
Para Timimi et al. (2004), existe certa ansiedade cultural que forneceu o contexto social ideal para o crescimento e a popularidade do conceito do TDAH, por exemplo, como uma doença biológica.
Ao mesmo tempo em que muitos problemas foram sendo incorporados ao campo médico, e que essa prática foi transformada em aceita e socialmente desejável, ocorreu também mudança de postura frente ao indivíduo medicalizado. De malvados, irresponsáveis, preguiçosos, mal-educados, dentre outros atributos, os indivíduos passaram a ser considerados doentes, não mais culpados por seu comportamento. Nessa linha de raciocínio, a correção desse comportamento deveria ser mais terapêutica do que punitiva (Conrad \& Schneider, 1992), já que o problema estaria no corpo biológico, no cérebro. Silva (2009) afirma que grande parte das crianças com TDAH, antes do diagnóstico, recebem vários rótulos e adjetivos pejorativos, que acabam por diminuir sua autoestima. Em outras palavras, conferir aos sofrimentos humanos o estatuto de doença, no caso das crianças, pode ser uma forma de libertação de seus estigmas morais de mau comportamento, desatenção e preguiça, dentre outros (Cruz, 2010). Além disso, essa forma de abordagem permite que muitas crianças que recebiam castigos diários ou que até mesmo eram expulsas da escola continuassem estudando.

Para Timimi et al. (2004), existe certa ansiedade cultural que forneceu o contexto social ideal para o crescimento e a popularidade do conceito do TDAH, por exemplo, como uma doença biológica. $\mathrm{O}$ autor defende a existência, por um lado, de uma pressão sobre pais e professores para que as crianças não quebrem as regras. Esses agentes seriam responsáveis por controlá-las. Ao mesmo tempo, existe também um tipo de inibição em exercer esse controle, um tipo de confusão entre o que é direito e o que é dever das crianças. Essa confusão pode gerar medo do julgamento dos demais e de uma intervenção do Estado. O transtorno mental aparece como uma solução viável, em que pais podem controlar o comportamento sem ferir, pelo menos legalmente, os direitos das crianças.

As facilidades em tomar uma pílula, em vez de enfrentar medos e situações não muito agradáveis, fazem com que as pessoas busquem o tratamento medicamentoso, com a promessa de alívio para suas dores e conflitos (Guarido, 2010). Em outras palavras, o modelo médico traz consigo uma visão otimista para o desvio, com a promessa de um resultado praticamente imediato. Acompanhando esse raciocício, as pessoas possuem confiança no profissional médico, autoridade quando se fala em saúde.

Mães de crianças com TDAH, apesar de não gostarem de dar um medicamento psicotrópico para o filho, o fazem, primeiramente, por ser uma recomendação médica, portanto, indiscutível. Em segundo lugar, existe uma pressão por parte da escola para que essa criança receba uma avaliação e um acompanhamento médicos. Por fim, existe ainda uma preocupação da adequação de seus filhos na sociedade, para que eles possam ter as mesmas oportunidades que os demais (Brzozowski, 2009).

O medicamento é o tratamento mais recomendado pelos especialistas em casos de TDAH infantil. As descobertas farmacêuticas, principalmente os medicamentos, promovidas por uma indústria altamente rentável e poderosa frequentemente se tornam o tratamento de escolha para comportamentos desviantes, isso porque eles são facilmente administrados sobre o controle profissional médico e potente em seus efeitos, além de serem geralmente menos caros do que outros tratamentos e controles médicos (como, por exemplo, psicoterapia e atendimento 
individualizado na escola) (Conrad \& Schneider, 1992).

Quando pensamos especificamente na escola, a medicalização dos processos de aprendizagem pode representar uma ajuda em sala de aula, pois resulta em crianças mais calmas e concentradas. Se há suspeita de algum transtorno mental e a criança é encaminhada a um profissional da saúde e se a suspeita for confirmada, a responsabilidade por aquela criança passa a não pertencer somente à escola, mas também aos profissionais da saúde que passarão a atendê-la. A efetividade de uma resposta rápida para o problema, principalmente nos casos em que serão prescritas medidas farmacológicas, faz que a prática dos encaminhamentos seja cada vez mais comum entre os professores (Brzozowski, 2009).

O aumento de explicações médicas para problemas de comportamento vem mudando nossas ideias sobre liberdade de escolha, desejos e responsabilidade pessoal por nossos comportamentos. Isso quer dizer que, se se considera que o comportamento agressivo de uma criança seja causado por uma anormalidade neurológica, então esse comportamento é encarado como se nem a criança nem seus pais pudessem conscientemente controlá-lo e que, portanto, requeresse assistência médica (Timimi, 2010). Como resultado, Brzozowski destaca que, quando uma criança encaminhada retorna à escola com um diagnóstico, ocorre uma mudança na forma de lidar com essa criança. Parece que o próprio diagnóstico gera um tipo de compreensão que estava até então ausente.

As novas descobertas científicas aparecem como as explicações mais aceitas para os diferentes comportamentos, sensações e sofrimentos humanos. A ciência acaba aparecendo como portadora da verdade, por meio de um discurso que ela mesma diz ser impessoal e ateórico. De acordo com Guarido (2010), a crítica à medicalização da vida não nega os avanços das pesquisas biológicas e dos tratamentos de doenças, mas procura refletir sobre as implicações que a biologização do ser humano pode ter para a própria condição humana.

Os aspectos posivitos do processo de medicalização dos comportamentos da infância parecem estar mais relacionados ao entorno das crianças do que a elas mesmas. Excetuando a maior compreensão de seu comportamento por parte dos adultos, não podemos afirmar com certeza até que ponto os demais fatores citados aqui beneficiam o próprio indivíduo medicalizado. A seguir, vamos refletir sobre o lado que consideramos negativo da medicalização da infância.

\section{Aspectos negativos}

A medicalização faz parte de um fenômeno maior que está muito presente em nossa sociedade, solidária com a estratégia de responsabilizar os indivíduos por problemas sociais. Isso significa dizer que tendemos a procurar as causas e as soluções de problemas sociais complexos nos indivíduos, em vez de buscá-los no próprio sistema social (Conrad \& Schneider, 1992). Dessa forma, os transtornos mentais infantis, principalmente os de aprendizagem, em termos biomédicos, são considerados de forma individual (Moyses \& Collares, 2010). A partir desse ponto de vista, determinado comportamento, portanto, não é o resultado de interações sociais e não pode ser explicado dessa forma. O comportamento é localizado somente no indivíduo, e assim será tratado. 
Essa prática de medicar um número cada vez maior de crianças tem como objetivo tratar sintomas, sem considerar 0 contexto em que essas crianças vivem e suas individualidades (Guarido, 2010).
Embora a imaturidade da criança seja um fato biológico, afinal, a criança ainda está em formação, o modo como essa imaturidade é entendida e gerida não o é. Isso quer dizer que o que é considerado um comportamento desejável em uma cultura ou em um período do tempo pode ser considerado abusivo em outro contexto (Timimi et al., 2004), ou seja, o comportamento socialmente desviante pode mudar, de acordo com a época e o meio em que se vive. Parece que estamos em um momento em que a falta de atenção, as dificuldades de aprendizagem e a agitação não são muito toleradas socialmente, e a forma que estamos lidando com isso é transfomar esses desvios em transtornos mentais.

A desculpa da doença para explicar um comportamento desviante só é válida quando o indivíduo aceita a perspectiva médica de que o seu comportamento não é adequado e se submete a uma relação de subordinação com um agente oficial de controle (no caso, o profissional de saúde), com o objetivo de mudar esse comportamento (Conrad \& Schneider, 1992). E o indivíduo aceita essa perspectiva quando ela própria é socialmente recomendada.

No caso das crianças, podemos pensar que isso pode ocorrer quando um indivíduo desatento na escola é encaminhado ao médico por não conseguir aprender como os seus colegas. Quando tal fato acontece, geralmente o entorno da criança (condições de vida, família e escola) e a possibilidade desse comportamento estar relacionado a esse entorno é ignorado. Para Illich (1975), nossa sociedade, superindustrializada e individualista, causa doenças, uma vez que as pessoas não conseguem adaptar-se a ela. O diagnóstico médico auxilia a explicar a não adaptação do indivíduo à sociedade. Ainda para o autor, a classificação de doenças que uma sociedade adota reflete sua estrutura institucional, e a origem social das doenças está na necessidade da isenção de culpa das instituições.

A produção de diagnósticos e de terapêuticas que simplificam os sofrimentos ocorridos na infância faz com que existam cada vez mais crianças medicadas (e cada vez mais cedo). O consumo global do metilfenidato, o principal fármaco utilizado no tratamento do TDAH, no período de 2003 a 2007, foi de 28,5 toneladas. Os Estados Unidos é o maior produtor e o maior consumidor do metilfenidato. No período entre 2005 a 2007, esse país consumiu uma média de 783 milhões de doses diárias desse fármaco, o que corresponde a aproximadamente $77 \%$ do consumo mundial da substância. No Brasil, em 2003, foram produzidos 86 kg de metilfenidato. Já em 2007, essa produção subiu para 204 kg, sem contar as importações (ONU, 2008). Essa prática de medicar um número cada vez maior de crianças tem como objetivo tratar sintomas, sem considerar o contexto em que essas crianças vivem e suas individualidades (Guarido, 2010).

Existe uma certeza, pelo menos no discurso hegemônico sobre o TDAH, de que se trata de uma doença biológica e que, por essa razão, é possível encontrar causas neurológicas para o transtorno, assim como ocorre com o restante da Medicina. Entretanto, existem diferenças entre as explicações etiológicas de doenças infecciosas, por exemplo, e de doenças mentais. As doenças infecciosas possuem um marcador biológico, exames que podem ser feitos para confirmar ou refutar o diagnóstico, diferentemente de uma doença psiquiátrica. Nesse caso, os marcadores estão relacionados aos mecanismos de ação dos medicamentos, e até hoje ainda são inconclusivos (Caponi, 2010). 
Além disso, há ainda o uso da Medicina como agente de controle social, por meio da intervenção médica e terapêutica. Conceitua-se controle social como as formas pelas quais a sociedade minimiza, elimina ou normaliza o comportamento desviante. Essa intervenção, da forma que caracteriza o controle social, busca limitar, modificar, regular, isolar ou eliminar os comportamentos desviantes por meios médicos e em nome da saúde (Conrad \& Schneider, 1992).

O principal papel do exame psiquiátrico é legitimar, por meio do conhecimento científico, "a extensão do poder de punir a outra coisa que não a infração" (Foucault, 2001, p. 23). Esse exame permite a transformação dos indivíduos, e a punição, ou a normalização, se dá por meio dessa transformação. Assim, são tomadas medidas corretivas, de readaptação ou de reinserção, visando à cura do indivíduo desviante.

O controle social médico inclui também informações e recomendações médicas, como por exemplo: todos precisam manter uma dieta balanceada, cigarro causa câncer, estar acima do peso aumenta o risco de ficar doente, exercício físico regular é saudável, os dentes precisam ser escovados regularmente. O não seguimento dessas diretrizes pode ser interpretado como um comportamento indesejável. E a resposta a esse não seguimento é a intervenção médica, que tem como objetivo a adesão desses indivíduos às normas de saúde (Conrad \& Schneider, 1992).

Se, por um lado, a medicalização de comportamentos desculpabiliza o indivíduo, por outro, a diminuição de responsabilidade que acompanha esse processo traz uma queda de status social. De acordo com Conrad e Schneider, a medicalizaçãofaz com que haja uma divisão entre os indivíduos considerados responsáveis por suas ações e aqueles que não são. Estes últimos são posicionados como dependentes dos demais.

Quando um problema é definido como médico, a discussão sobre ele é removida do âmbito coletivo e levada para a área da saúde. Em outras palavras, a população em geral tem suas próprias concepções sobre que é ou não um comportamento desviante, mas as definições dos especialistas geralmente são as dominantes (Conrad \& Schneider, 1992).

Passando o problema para o âmbito médico, é natural que o tratamento se dê de modo semelhante ao que ocorre no restante da Medicina. Por essa razão, uma das formas que a Medicina adota atualmente como controle dos desvios é a medicamentalização, ou seja, o tratamento farmacológico como consequência da transformação de problemas de vida em problemas médicos (Faraone, Barcala, Torricelli, Bianchi, \& Tamburrino, 2010). Isso significa dizer que vários problemas que antes eram considerados cotidianos passaram a fazer parte do escopo médico e a ser tratados com medicamentos. O grande problema é que uma intervenção realizada somente no campo da medicação não escuta o sofrimento do outro, o que implica necessariamente um reducionismo da terapêutica (Guarido, 2010).

Peter Breggin (2002) afirma que os estimulantes, incluindo o metilfenidato (cujo nome comercial mais conhecido é a Ritalina ${ }^{\circledR}$ ), principal tratamento em casos de TDAH, agem pela supressão da habilidade cerebral de gerar comportamentos mentais espontâneos. Esses medicamentos interrompem as conexões nas regiões mais desenvolvidas do cérebro, incluindo os lobos frontais, sedes dos comportamentos mais complexos. Para esse autor, a utilização 
do metilfenidato é um tipo de lobotomia química.

Por fim, outro fator importante a considerar quando falamos em medicalização da infância é o resultado que o diagnóstico, ou a classificação, pode ter para a própria criança classificada. Ian Hacking (2006) afirma que os indivíduos classificados interagem com sua classificação, e tanto indivíduo quanto classificação podem se modificar em razão dessa interação, processo que o autor chamou de efeito de arco $^{7}$, que pode apresentar um feedback positivo, quando a classificação interage com o indivíduo no sentido de exacerbar as características associadas a essa classificação, ou então negativo, quando essa interação ameniza ou nega essas características.

Tal processo pode ocorrer em casos de diagnósticos de doenças mentais em crianças. Mesmo que a criança seja muito pequena para compreender o sentido de seu diagnóstico, ela sente as mudanças que ocorrem na escola e na família, e pode também sofrer efeito de arco. E esse efeito pode ser positivo, fazendo com que essa criança passe a justificar suas atitudes em razão da classificação (Brzozowski \& Caponi, 2009).

\section{Considerações finais}

A Medicina vem sendo vista, e por que não dizer utilizada, como escoadouro de alguns problemas crônicos, principalmente comportamentais, que aparecem predominantemente na escola. Pela aparente resolutividade, a psiquiatria, as neurociências e a farmacologia vêm ganhando força e legitimação social para se responsabilizar por esses problemas, e a resposta do sistema de saúde a essa demanda com desvios de comportamentos, tais como transtorno bipolar, depressão e TDAH (Cruz, 2010). Existe, assim, o perigo da expansão da categoria diagnóstica, que englobaria dentro dessas classificações um número cada vez maior de indivíduos (Conrad, 2007).

Com a medicalização, questões sociais tornam-se biológicas, o que naturaliza a vida e todos os processos sociais nela envolvidos. Dessa forma, explica-se um quadro complexo, que envolve questões psicológicas e sociais, apenas por meio do desequilíbrio de um ou mais neurotransmissores no cérebro. Dentro desse formato explicativo, as instâncias de poder podem facilmente ser isentas de algumas responsabilidades, tais como diminuir as desigualdades sociais ou oferecer um ensino de qualidade, que respeite as individualidades, já que os problemas estão no âmbito de doenças neurológicas, tratáveis com medicamentos.

Além disso, o processo de medicalização retira a possibilidade de atuação dos sujeitos sobre $o$ que lhes acontece, já que os problemas, como os de aprendizagem, por exemplo, seriam o resultado apenas de um desequilíbrio cerebral. O indivíduo desresponsabilizado por seus comportamentos (não é mais o indivíduo, e sim, o seu cérebro) torna-se impotente diante de seu sofrimento, sendo o médico o único capaz de saber o que fazer (Guarido, 2010).

Fazer uma crítica ao diagnóstico excessivo de doenças mentais não tem como objetivo negar os sofrimentos humanos, como muitos podem afirmar. Pelo contrário, tem como objetivo alertar a sociedade sobre: (1) o uso excessivo de medicamentos, que podem apresentar inúmeros efeitos adversos, (2) a transformação de situações que poderiam ser resolvidas sem a interferência médica em 
doenças, (3) o uso comercial que as grandes empresas da saúde fazem do sofrimento humano e (4) a falta de apoio e de reflexão social sobre a configuração de nossa própria sociedade e de suas instituições (escola, sistemas de saúde e assistência social).

A medicalização e o tratamento dos comportamentos desviantes são considerados um avanço da Medicina, sinal do progresso da sociedade. Talvez, em alguns aspectos, a medicalização do vício em opiáceos, alcoolismo, obesidade, loucura e outros comportamentos seja mesmo um progresso. As mudanças definidas como progresso, por sua vez, devem ser vistas como progresso para certos indivíduos em particular, e que não necessariamente beneficiarão a todos igualmente (Conrad \& Schneider, 1992).

Apesar de as intervenções médicas serem julgadas por sua eficácia, as consequências sociais da medicalização ocorrem independentemente dessa eficácia médica (Conrad, 1992). Em nossa sociedade, o modelo da medicina científica, muito valorizado, possui um poder muito grande: a maior parte da população assume como verdade se essa medicina afirma que determinados comportamentos são, na realidade, doenças (Timimi, 2002).

A resposta social imediata diante de um diagnóstico de transtorno mental leve em uma criança é de compreensão, paciência. Pais, professores, profissionais de saúde e vizinhos se tornam mais tolerantes, afinal, não é mais culpa da criança, mas sim, de seu cérebro. Esse modo de ver a infância, porém, também apresenta consequências negativas. Primeiramente, a utilização de um medicamento estimulante, de mecanismo de ação e de resultado a longo prazo, um tanto incertos, que pode trazer efeitos danosos a esses cérebros em desenvolvimento.

Outro fator importante é o monopólio da informação por parte da área médica/ científica. Para a população, chegam apenas as informações sobre como reconhecer, como tratar e como lidar. A discussão de critérios, de inclusão e de exclusão de características, o que é ou não sintoma fica restrito apenas a um conjunto de profissionais de saúde.

O número elevado de crianças encaminhadas ao profissional de saúde, muitas delas diagnosticadas com TDAH, por exemplo, alerta para uma das consequências de um excesso de medicalização dos comportamentos considerados anormais na escola: tratar como patológicos comportamentos que, na realidade, são normais. Podemos ir mais além e pensar quais as consequências de se designar alguém tão cedo com um diagnóstico desse tipo: (1) a criança pode justificar seu comportamento por meio do transtorno, (2) sua família e até ela mesma pode considerarse capaz de determinadas atividades apenas se estiver em tratamento, (3) tudo isso pode fazer que a criança e, quando crescer, o adulto, se torne dependente (não no sentido de dependência física) do diagnóstico, agindo apenas de acordo com o que se espera dela como portadora do transtorno.

A ideia de que comportamentos, e também estados de ânimo (Hernaez, 2010), podem ser convertidos em problemas mentais é o sintoma de uma lógica de dessocialização. Ao mesmo tempo em que a medicalização e a mercantilização da saúde geram a busca pelo medicamento psicotrópico e pelo diagnóstico de uma doença para alívio de um sofrimento, dissimulam também as relações sociais que podem ter relação com esse sofrimento.

Mais uma vez, deixamos claro que nosso 
objetivo, de maneira nenhuma, é negar o sofrimento das famílias e das crianças que apresentam algum tipo de comportamento desviante. E também não negamos que esses comportamentos precisam receber atenção. Apenas alertamos para a possibilidade de discussão sobre outros tipos de abordagem possíveis que não apenas a biológica, ou até mesmo de uma rediscussão mais ampla do papel dos processos e das instituições educacionais e médicas. 


\section{Fabíola Stolf Brzozowski}

Doutoranda em Saúde Coletiva pela Universidade Federal de Santa Catarina, Florianópolis - SC - Brasil.

E-mail: fabijerzy@yahoo.com

\section{Sandra Noemi Cucurullo de Caponi}

Doutora em Lógica e Filosofia da Ciência pela Universidade Estadual de Campinas e professora da Universidade Federal de Santa Catarina, Florianópolis - SC - Brasil.

E-mail: sandracaponi@gmail.com

Endereço para envio de correspondência:

Rua Douglas Seabra Levier, 163, ap. 203E. CEP: 88040-410 . Florianópolis, SC

Recebido 27/03/2012, 1a Reformulação 06/11/2012, Aprovado 29/11/2012 


\section{Referências}

Ariès, P. (1981). História social da criança e da família (2a ed.). Rio de Janeiro: LTC.

Breggin, P. R. (2002). The Ritalin fact book: What your doctor won't tell you about ADHD and stimulant drugs. Cambridge: Perseus Publishing.

Brzozowski, F. S. (2009). Transtorno de déficit de atenção com hiperatividade: medicalização, classificação e controle dos desvios. Dissertação de mestrado. Programa de Pós-Graduação em Saúde Pública, Universidade Federal de Santa Catarina, Florianópolis, SC.

Brzozowski, F. S., \& Caponi, S. (2009). Transtorno de déficit de atenção com hiperatividade: classificação e classificados. Physis Revista de Saúde Coletiva, 19(4), 1165-87.

Caponi, S. (2010). O diagnóstico de depressão, a "petite biologie" e os modos de subjetivação. In S. Caponi, M. Verdi, F. S. Brzozowski \& F. Hellmann (Orgs.). Medicalização da vida: ética, saúde pública e indústria farmacêutica (pp. 135-143). Palhoça, SC: Unisul.

Conrad, P. (1992). Medicalization and social control. Annual Review of Sociology, 18, 209-32.

Conrad, P. (2007). The medicalization of society: On the transformation of human conditions into treatable disorders. Baltimore: The John Hopkins University Press.

Conrad, P., \& Schneider, J. W. (1992). Deviance and medicalization: From badness to sickness. Philadelphia: Temple University Press.

Cruz, M. A. S. (2010). Desafios da clínica contemporânea: novas formas de "manicomialização". In CRP-SP (Conselho Regional de Psicologia de São Paulo) (Orgs.). Medicalização de crianças e adolescentes: conflitos silenciados pela redução de questões sociais a doenças de indivíduos (pp. 17-25). São Paulo: Casa do Psicólogo.

Faraone, S., Barcala, A., Torricelli, F., Bianchi, E., \& Tamburrino, M. C. (2010). Discurso médico y estrategias de marketing de la industria farmacéutica en los procesos de medicación de la infancia en Argentina. Interface - Comunicação, Saúde, Educação, 14(34), 485-97.

Foucault, M. (2001). Os anormais. São Paulo: Martins Fontes.

Guarido, R. (2010). A biologização da vida e algumas implicações do discurso médico sobre a educação. In CRP-SP (Conselho Regional de Psicologia de São Paulo) (Orgs.). Medicalização de crianças e adolescentes: conflitos silenciados pela redução de questões sociais a doenças de indivíduos (pp. 29-39). São Paulo: Casa do Psicólogo.
Hacking, I. (2006). O autismo: o nome, o conhecimento, as instituições, os autistas - e suas interações. In M. Russo \& S. Caponi (Orgs.). Estudos de filosofia e história das ciências biomédicas (pp. 305-320). São Paulo: Discurso Editorial.

Hernaez, A. M. (2010). A medicalização dos estados de ânimo: o consumo de antidepressivos e as novas biopolíticas das aflições. In S. Caponi, M. Verdi, F. S. Brzozowski \& F. Hellmann (Orgs.). Medicalização da vida: ética, saúde pública e indústria farmacêutica (pp. 111-134). Palhoça, SC: Unisul.

Horwitz, A. V. (2007). The loss of sadness: How psychiatry transformed normal sorrow into depressive disorder. New York: Oxford University Press.

Illich, I. (1975). A expropriação da saúde: nêmesis da medicina (3a. ed.). Rio de Janeiro: Nova Fronteira.

Moyses, M. A. A., \& Collares, C. A. L. (2010). Dislexia e TDAH: uma análise a partir da ciência médica. In CRP-SP (Conselho Regional de Psicologia de São Paulo) (Orgs.). Medicalização de crianças e adolescentes: conflitos silenciados pela redução de questões sociais a doenças de indivíduos (pp. 71-110). São Paulo: Casa do Psicólogo.

ONU - Organização das Nações Unidas. International Narcotics Control Board. (2008). Psychotropic substances: Statistics for 2007: assessments of annual medical and scientific requirement. Recuperado em 2 dez., 2010, de http://www.incb.org/pdf/technicalreports/psychotropics/2008/psy_2008.pdf.

Rocha, H. H. P. (2003). Educação escolar e higienização da infância. Cadernos CEDES, 23(59), 39-56.

Rose, N. (2006). Disorders without borders? The expanding scope of psychiatric practice. BioSocieties, $1,465-84$.

Silva, A. B. B. (2009). Mentes inquietas: TDAH: desatenção, hiperatividade e impulsividade. Rio de Janeiro: Objetiva.

Szasz, T. (1974). O mito da doença mental. São Paulo: Círculo do Livro, S.A.

Timimi, S. (2002). Pathological child psychiatry and the medicalization of childhood. New York: BrunnerRoutledge.

Timimi, S. (2010). The McDonaldization of childhood: Children's mental health in neo-liberal market cultures. Transcultural Psychiatry, 47(5), 686-706.

Timimi, S., Moncrieff, J., Jureidini, J., Leo, J., Cohen, D., Whitfield, C. et al. (2004). A critique of the International Consensus Statement on ADHD. Clinical Child and Family Psychology Review, 7(1), p. 59-63. 